\title{
SELF- ACCEPTANCE DAN EMPOWERMENT PADA PASIEN KATARAK
}

\author{
Chindy Maria Orizani \\ Akademi Keperawatan Adi Husada Surabaya \\ chindyorizani@gmail.com
}

\begin{abstract}
ABSTRAK
Sebagian penderita katarak mengalami ketidakberdayaan dalam melakukan kegiatan biasanya yang dilakukan karena penurunan kemampuan melihat sehingga sangat rentan terjadi cedera, maka agar penderita katarak tidak mengalami ketidakberdayaan memerlukan penerimaan diri (self-acceptance) dengan dapat menyadari dan mengakui karakteristik pribadi dan menggunakannya dalam menjalani kelangsungan hidupnya secara bermakna sehingga dapat mengendalikan situasi saat ini atau yang akan terjadi. Tujuan dari penelitian ini untuk mengidentifikasi hubungan penerimaan diri dan keberdayaan pada pasien katarak. Jenis penelitian ini adalah korelasional dengan pendekatan cross sectional. Sampel penelitian sebanyak 40 penderita katarak dengan menggunakan tehnik consecutive sampling. Data dianalisis dengan menggunakan uji koefisien kontingensi. Hasil menunjukkan sebagian besar responden berusia 66-75 tahun, laki-laki, berpendidikan terakhir SMP, memiliki penghasilan antara Rp.500.000,00-Rp. 1.000.000,00, pensiunan, lama menderita katarak antara 1 - 3 tahun dan menggunakan fasilitas kesehatan rumah sakit. Hasil menunjukkan mayoritas responden menerima kondisi tubuh dan berdaya, dengan $\mathrm{p}=0,000$ dan $\mathrm{r}=0,614$, yaitu terdapat hubungan kuat antara penerimaan diri dan empowerment pada penderita katarak. Perubahan pada penderita katarak tidak mempengaruhi penerimaan dirinya, karena responden beranggapan penyakit sudah wajarnya terjadi pada lansia.Diharapkan peran perawat dapat ditingkatkan terutama dalam memberikan edukasi pada penderita katarak \& keterlibatan keluarga dalam perawatan.
\end{abstract}

Kata kunci: penerimaan diri, empowerment, pasien katarak

\begin{abstract}
Most cataract patients experienced powerlessness in activities normally performed due to decreased ability to see so highly susceptible to injury, so that cataract patients do not experience the powerlessness requires self-acceptance to be able to realize and acknowledge personal characteristics and use them in carrying out their survival significantly so as to control the situation current or expected. The purpose of this study to identify a correlation of self-acceptance and empowerment in cataract patients. This type of research is correlational study with cross sectional approach. The research sample were 40 patients with cataract using consecutive sampling technique. Data were analyzed using contingency coefficient test. The results showed that most of the respondents aged 6675 years old, male, junior high school education, have an income between Rp.500.000,00-Rp. 1.000.000,00, retirees, long suffering from cataract between 1-3 years and using hospitals as health facilities. The results showed the majority of respondents accept the condition of the body and empowerment, with $p=0.000$ and $r=0.614$, so there was a strong correlation between selfacceptance and empowerment in cataract patients. Changes in people with cataracts do not affect the self-acceptance itself, because respondents think the disease is already fair occur in the elderly. Expected role of nurses could be improved, especially in educating the cataract patient and family involvement in care.
\end{abstract}

Keywords: self-acceptance, empowerment, cataract patients

\section{PENDAHULUAN}

Katarak merupakan kelainan mata yang terjadi akibat adanya perubahan lensa yang jernih dan tembus cahaya, sehingga keruh akibatnya mengalami gangguan penglihatan karena obyek menjadi kabur. Gangguan penglihatan yang terjadi tidak secara spontan, melainkan secara perlahan dan dapat menimbulkan kebutaan. Oleh sebab itu, sebagian penderita katarak mengalami ketidakberdayaan dalam melakukan kegiatan biasanya yang dilakukan karena penurunan kemampuan melihat sehingga sangat rentan terjadi cedera, maka agar penderita katarak tidak mengalami ketidakberdayaan memerlukan penerimaan diri dengan dapat menyadari dan mengakui karakteristik pribadi dan menggunakannya dalam menjalani kelangsungan hidupnya secara bermakna 
sehingga dapat mengendalikan situasi saat ini atau yang akan terjadi.

Prevalensi kekeruhan kornea nasional adalah 5,5\% dengan prevalensi tertinggi jugaditemukan di Bali (11,0\%), diikuti oleh DI Yogyakarta $(10,2 \%)$ dan Sulawesi Selatan (9,4\%). Prevalensi kekeruhan kornea terendah dilaporkan di Papua Barat (2,0\%) diikuti DKI Jakarta(3,1\%). Prevalensi kekeruhan kornea yang tinggi pada kelompok pekerjaan petani/nelayan/buruh mungkin berkaitan dengan riwayat trauma mekanik atau kecelakaan kerja pada mata, mengingat pemakaian alat pelindung diri saat bekerja belum optimal dilaksanakan di Indonesia. ${ }^{5}$

Dampak dari katarak biasanya akan terjadi keburaman dalam lensa, kemudian pembengkakan lensa, dan penyusutan akhir dengan kehilangan transparasi seluruhnya. Selain itu, lapisan luar katarak akan mencair dan membentuk cairan putih susu, yang dapat menyebabkan peradangan berat jika pecah kapsul lensa dan terjadi kebocoran. Bila tidak dioperasi, katarak dapat menyebabkan glaukoma. Berdasarkan dampak tersebut merupakan penyebab penderita katarak tidak dapat menerima keadaannya untuk menjalani kelangsungan hidupnya seperti melakukan pemenuhan kebutuhan sehari-harinya dengan tidak bergantung dengan orang lain.

Penderita katarak merasa tidak nyaman dengan keadaan yang dialaminya karena menyebabkan tidak dapat melakukan kegiatan yang biasanya dilakukan sehari-hari maka penderita katarak mengalami ketidakberdayaan. Penderita katarak mengalami ketidakberdayaan, muncul beberapa faktor yaitu dapat mengalami frustasi dengan kondisi kesehatannya dan kehidupannya yang sekarang, mengalami perubahan perilaku dan psikososial seperti mudah marah, merasa cemas, sulit berkonsentrasi, sering bermimpi buruk dan merasa cemas. Penderita katarak mempunyai self control yaitu tidak mampu mengontrol perasaan seperti emosi, marah dan dapat bersikap pasif. ${ }^{7}$ Seseorang yang mengalami ketidakberdayaan dalam melakukan kegiatan sehari-harinya tidak akan mempunyai karakteristik yang muncul seperti memiliki penilaian realistis terhadap potensi-potensi yang dimiliki, menyadari kekurangan tanpa menyalahkan diri sendiri, memiliki spontanitas dan tanggungjawab terhadap perilakunya, dan menerima kualitas kemanusiaan mereka tanpa menyalahkan diri sendiri terhadap keadaan di luar kendali. ${ }^{8}$ Oleh sebab itu, pada lansia yang menderita katarak tersebut mengharapkan dapat melakukan kegiatan sehari-harinya dengan sendiri atau mandiri tanpa bantu orang lain atau alat. Dengan adanya rasa penerimaan diri yang meliputi adanya perasaan bebas dari rasa takut dan cemas untuk mengembangkan dirinya secara optimal sesuai kemampuan yang dimiliki penderita katarak tidak mengalami ketidakberdayaan dalam melakukan kegiatan sehari-harinya. Berdasarkan uraian tersebut maka peneliti tertarik untuk meneliti hubungan penerimaan diri dengan empowerment pada penderita katarak.

\section{METODE}

Jenis penelitian ini adalah korelasional dengan pendekatan cross sectional. Populasi dari penelitian ini adalah seluruh penderita katarak di Kelurahan Kedurus, Kecamatan Karangpilang, Surabaya Sampel penelitian sebanyak 40 penderita katarak dengan menggunakan tehnik consecutive sampling. Penelitian dilaksanakan pada Bulan Mei 2016 di Kelurahan Kedurus, Kecamatan Karangpilang, Surabaya. Data yang didapatkan dianalisa dengan menggunakan piranti lunak statistik yaitu dengan menggunakan tabel frekuensi dan uji koefisien kontingensi.

\section{HASIL}

\section{Data Umum}

Tabel 1. Karakteristik Responden

\begin{tabular}{|c|c|c|c|}
\hline No & Karakteristik & $\mathbf{n}$ & $\%$ \\
\hline \multirow[t]{4}{*}{1} & Umur (Tahun) & & \\
\hline & $55-65$ & 14 & 35 \\
\hline & $66-75$ & 22 & 55 \\
\hline & $>75$ & 4 & 10 \\
\hline \multirow[t]{3}{*}{2} & Jenis Kelamin & & \\
\hline & Perempuan & 17 & 42,5 \\
\hline & Laki-laki & 23 & 57,5 \\
\hline \multirow[t]{4}{*}{3} & Status Perkawinan & & \\
\hline & Belum kawin & 0 & 0 \\
\hline & Janda/duda & 13 & 32,5 \\
\hline & Kawin & 27 & 67,5 \\
\hline \multirow[t]{6}{*}{4} & Pendidikan & & \\
\hline & Tidak sekolah & 4 & 10 \\
\hline & SD & 9 & 22,5 \\
\hline & SLTP & 14 & 35 \\
\hline & SLTA & 7 & 17,5 \\
\hline & $\mathrm{D} 3 / \mathrm{S} 1 / \mathrm{S} 2 / \mathrm{S} 3$ & 6 & 15 \\
\hline \multirow[t]{4}{*}{5} & Penghasilan & & \\
\hline & $<500.000$ & 5 & 12,5 \\
\hline & $500.000-1.000 .000$ & 19 & 47,5 \\
\hline & $>1.000 .000$ & 16 & 40 \\
\hline \multirow[t]{2}{*}{6} & Pekerjaan & & \\
\hline & Tidak bekerja & 4 & 10 \\
\hline
\end{tabular}




\begin{tabular}{llcc}
\hline $\begin{array}{l}\text { Buruh/pegawai tidak } \\
\text { tetap }\end{array}$ & 5 & 12,5 \\
\hline Pensiunan/PNS/ABRI & 17 & 42,5 \\
\hline Wiraswasta & 3 & 7,5 \\
\hline & Swasta & 11 & 27,5 \\
\hline $7 \quad$ Lama menderita & & \\
\hline$\quad$ <1 tahun & 6 & 15 \\
\hline $1-3$ tahun & 28 & 70 \\
\hline >3 tahun & 6 & 15 \\
\hline $8 \quad$ Fasilitas Kesehatan & & \\
\hline & Rumah sakit & 37 & 92,5 \\
\hline & 3 & 7,5 \\
\hline Puskesmas & 0 & 0 \\
\hline Balai pengobatan & 0 & 0 \\
\hline Alternatif & &
\end{tabular}

Karakteristik responden berdasarkan umur terdapat 22 responden $(55 \%)$ pada golongan 66-75 tahun banyak menderita katarak karena berkaitan dengan proses penuaan pada lensa. Karakteristik responden berdasarkan jenis kelamin terdapat 23 responden $(57,5 \%)$ yang menderita katarak adalah laki-laki yang banyak mengalami penuaan. Karakteristik responden berdasarkan status perkawinan terdapat 27 responden $(67,5$ $\%$ ) yang status perkawinannya adalah kawin. Karakteristik responden berdasarkan pendidikan terdapat 14 responden (35\%) mempunyai tingkat pendidikan SLTP mempengaruhi sosial ekonomi penderita. Karakteristik responden berdasarkan penghasilan terdapat 19 responden $(47,5 \%)$ mempunyai penghasilan 500.000-1.000.000. Karakteristik responden berdasarkan pekerjaan terdapat 17 responden $(42,5 \%)$ pada pensiunan/PNS/ABRI. Karakteristik responden berdasarkan lama menderita terdapat 28 responden (70\%) yaitu 1-3 tahun menderita katarak. Karakteristik responden berdasarkan fasilitas kesehatan terdapat 37 responden $(92,5$ $\%$ ) fasilitas kesehatan yang didatangi yaitu rumah sakit yang melayani tindakan operasi katarak.

\section{PEMBAHASAN}

Berdasarkan hasil penelitian maka tingginya penerimaan diri didapatkan pada responden yang berusia 66-75 tahun. Usia mempengaruhi kematangan mental, kecerdasan emosional dan spiritual masingmasing individu, dimana pada individu yang berusia jauh lebih tua memiliki pengalaman hidup jauh lebih banyak sehingga kemampuan individu dalam melakukan koping saat mengalami masalah jauh lebih baik dibandingkan usia yang lebih muda. ${ }^{2}$
Beberapa faktor yang mempengaruhi penerimaan diri, antara lain: adanya pemahaman tentang diri sendiri, adanya hal yang realistik, tidak adanya hambatan di sekitar lingkungan, sikap support system, tidak adanya gangguan emosional yang berat, pengaruh keberhasilan yang dialami individu, adanya perspektif diri yang luas, pola asuh masa kecil yang baik, dan konsep diri yang baik. ${ }^{4}$ Individu lanjut usia yang dapat menerima perubahan berkaitan dengan proses penuaan akan menunjukkan semangat dan gembira dalam menjalani kehidupan masa tuanya. Hal ini disebabkan individu dengan penerimaan diri memiliki toleransi terhadap stressor atau kejadian yang menjengkelkan, dan toleransi terhadap kelemahan dirinya tanpa harus menjadi sedih atau marah. Individu dapat menerima dirinya sebagai seorang manusia yang memiliki kelebihan dan kelemahan. Jadi, individu yang mampu menerima dirinya adalah individu yang dapat menerima kekurangan dirinya sebagaimana kemampuannya untuk menerima kelebihannya.

Hampir semua responden mempunyai keluarga yang mengetahui masalah kesehatan yang dialami penderita atau mungkin dapat memutuskan tindakan yang tepat untuk penderita. Hal ini dapat sesuai dengan tugas kesehatan keluarga dimana keluarga mampu memberikan perawatan pada anggota keluarganya yang sakit. ${ }^{3}$ Keluarga sebagai support system terutama dukungan emosional yang dapat membuat penderita katarak merasa terlindungi dan berdaya. Hal yang dapat merubah kondisi pada penderita katarak yaitu individu dapat melihat potensi pada dirinya dan mampu melakukan aktivitas secara optimal, tidak tergantung sepenuhnya pada orang lain namun belajar untuk mandiri walaupun memiliki keterbatasan. Selain itu, penderita mempunyai kondisi emosi yang menyenangkan, penyesuaian dirinya baik, adanya pemahaman diri, dan sikap lingkungan sosial yang menyenangkan, dimana hati yang senang merupakan obat.

\section{SIMPULAN}

Terdapat hubungan antara penerimaan diri dengan empowerment penderita katarak dimana penderita katarak menerima kondisi perubahan yang terjadi setelah didiagnosa katarak. Responden menyatakan penyakit yang datang saat masa lansia adalah wajar sehingga responden sudah siap, keluarga pun memberikan dukungan terhadap anggota 
keluarga yang menderita katarak dengan pemenuhan kebutuhan hariannya.

\section{SARAN}

Diharapkan dari hasil penelitian ini, peran perawat dapat ditingkatkan terutama dalam hal memberikan pendidikan kesehatan tentang katarak dan dukungan terhadap para penderita katarak. Perawat juga diharapkan mengembangkan program pendidikan kesehatan melalui pendekatan perilaku kognitif untuk meningkatkan penerimaan diri dan empowerment penderita katarak. Bagi keluarga diharapkan berperan aktif dalam mendukung dan pemenuhan kebutuhan harian anggota keluarga yang mengalami katarak.

\section{DAFTAR PUSTAKA}

1. Dewi, Sofia R. 2014. Buku Ajar Keperawatan Gerontik. Yogjakarta: Deepublish.

2. Goleman, Daniel. 2007. Kecerdasan Emosional. Jakarta: Gramedia

3. Haji, Zaidin Ali. 2009. Pengantar Keperawatan Keluarga. Jakarta: EGC

4. Hurlock, Elisabeth B. 2003. Psikologi Perkembangan: Suatu Pendekatan Sepanjang Kehidupan. Jakarta: Erlangga

5. Kemenkes RI. 2013. Riset Kesehatan Dasar Tahun 2013. Jakerta: Kemenkes RI

6. Muhith, Abdul. 2015. Pendidikan Keperawatan Jiwa Teori dan Aplikasi. Yogjakarta: Andi.

7. Santoso \& Ismail. 2009. Memahami Krisis Lanjut Usia. Jakarta: Gunung Mulia

8. Videbeck, Sheila L. 2008. Buku Ajar Keperawatan Jiwa. Jakarta: EGC 